ARTICLE

Received 2 Feb 2016 | Accepted 2 Jun 2016 | Published 30 Jun 2016

DOI: $10.1038 /$ ncomms12123

OPEN

\title{
Highly selective plasma-activated copper catalysts for carbon dioxide reduction to ethylene
}

Hemma Mistry², Ana Sofia Varela ${ }^{3}$, Cecile S. Bonifacio ${ }^{4}$, loannis Zegkinoglou², llya Sinev², Yong-Wook Choi², Kim Kisslinger ${ }^{5}$, Eric A. Stach ${ }^{5}$, Judith C. Yang ${ }^{4}$, Peter Strasser ${ }^{3} \&$ Beatriz Roldan Cuenya ${ }^{2}$

There is an urgent need to develop technologies that use renewable energy to convert waste products such as carbon dioxide into hydrocarbon fuels. Carbon dioxide can be electrochemically reduced to hydrocarbons over copper catalysts, although higher efficiency is required. We have developed oxidized copper catalysts displaying lower overpotentials for carbon dioxide electroreduction and record selectivity towards ethylene (60\%) through facile and tunable plasma treatments. Herein we provide insight into the improved performance of these catalysts by combining electrochemical measurements with microscopic and spectroscopic characterization techniques. Operando $\mathrm{X}$-ray absorption spectroscopy and crosssectional scanning transmission electron microscopy show that copper oxides are surprisingly resistant to reduction and copper $^{+}$species remain on the surface during the reaction. Our results demonstrate that the roughness of oxide-derived copper catalysts plays only a partial role in determining the catalytic performance, while the presence of copper $^{+}$is key for lowering the onset potential and enhancing ethylene selectivity.

\footnotetext{
${ }^{1}$ Department of Physics, University of Central Florida, Orlando, Florida 32816, USA. ${ }^{2}$ Department of Physics, Ruhr-University Bochum, 44780 Bochum, Germany. ${ }^{3}$ Department of Chemistry, Chemical Engineering Division, Technical University Berlin, 10623 Berlin, Germany. ${ }^{4}$ Chemical and Petroleum Engineering and Physics, University of Pittsburgh, Pittsburgh, Pennsylvania 15261, USA. ${ }^{5}$ Center for Functional Nanomaterials, Brookhaven National Laboratory, Upton, New York 11973, USA. Correspondence and requests for materials should be addressed to B.R.C. (email: beatriz.roldan@rub.de).
} 
T he development of technologies to capture and convert carbon dioxide $\left(\mathrm{CO}_{2}\right)$-a greenhouse gas released by the burning of fossil fuels-to useful products is critically needed to mitigate global warming. The electrocatalytic reduction of $\mathrm{CO}_{2}\left(\mathrm{CO}_{2} \mathrm{RR}\right)$ shows promise as a viable $\mathrm{CO}_{2}$ utilization process since it can occur under ambient conditions and low cost copper $(\mathrm{Cu})$ catalysts can facilitate the reduction pathway to hydrocarbons ${ }^{1-3}$. However, more efficient catalysts are still required because large overpotentials are required for bulk $\mathrm{Cu}$ to reduce $\mathrm{CO}_{2}$ to hydrocarbon products (methane and ethylene) while competing with the hydrogen evolution side reaction ${ }^{4-8}$. Efficient $\mathrm{Cu}$ catalysts with high selectivity to ethylene are especially desirable due to the value of ethylene as a widely used chemical feedstock.

Investigations in recent years have led to the development of many interesting metal-based catalytic materials for $\mathrm{CO}_{2} \mathrm{RR}$. Nanostructured catalysts such as nanoparticles ${ }^{9-14}$, nanocubes ${ }^{15,16}$, nanofoams ${ }^{17}$ and nanowires ${ }^{18}$ have shown vastly improved activity or selectivity over bulk materials ${ }^{19,20}$. Recently, nanostructures derived from the reduction of copper oxides have shown vastly improved $\mathrm{CO}_{2}$ reduction efficiency at lower overpotentials ${ }^{21-24}$. These materials were synthesized from the reduction of thermally oxidized $\mathrm{Cu}$ or electrodeposited copper(I) oxide $\left(\mathrm{Cu}_{2} \mathrm{O}\right)$, and in general display improved current density, enhanced $\mathrm{CO}_{2}$ reduction to carbon monoxide (CO) at low overpotentials, and a partial suppression of methane $\left(\mathrm{CH}_{4}\right)$ in favour of ethylene $\left(\mathrm{C}_{2} \mathrm{H}_{4}\right)$ at higher overpotentials. Despite these promising results, the mechanism behind the reactivity trends of oxide-derived $\mathrm{CO}_{2} \mathrm{RR}$ catalysts is still under dispute. Grain boundaries in oxide-derived $\mathrm{Cu}$ have been suggested to support unique surface sites which may be active for $\mathrm{CO}_{2} \mathrm{RR}^{22,25,26}$. Another mechanism could be the increase in local $\mathrm{pH}$ due to high current densities ${ }^{27}$ on the highly roughened surfaces, which could alter the reaction pathway in favour of ethylene ${ }^{28-30}$. Alternatively, the nanostructuring of the catalyst surface during the oxide reduction may also provide low-coordinated atoms as active sites $9 . \mathrm{Cu}^{\delta+}$ sites which may remain on the catalyst surface during the reaction have also been suggested to be the active sites $^{31-35}$. However, no operando evidence of this claim exists up to this point, and only ex situ evidence has been presented. This ex situ evidence is complicated by the rapid formation of native oxides on metallic $\mathrm{Cu}$ surfaces upon removal from the reactor and exposure to air ${ }^{23}$. In general, it has been assumed that $\mathrm{Cu}$ oxides are completely reduced during the relatively high $\mathrm{CO}_{2} \mathrm{RR}$ potentials used (that is, $\sim 1 \mathrm{~V}$ versus reversible hydrogen electrode (RHE)), and that the reaction occurs only on metallic $\mathrm{Cu}$ species.

Oxygen plasma treatment is a facile and scalable technique to controllably oxidize and nanostructure metal catalysts for $\mathrm{CO}_{2} \mathrm{RR}$ that has not yet been explored. Plasma treatment is a powerful method to activate catalysts, for example by removing capping ligands used in the synthesis of nanoparticles without sintering $^{36,37}$, by rapidly changing the chemical state of the surface at room temperature 38,39 , or by creating defects or embedded atoms which can improve reactivity ${ }^{40}$. We have used oxygen $\left(\mathrm{O}_{2}\right)$ and hydrogen $\left(\mathrm{H}_{2}\right)$ plasmas to create novel nanostructured oxide layers and porous surfaces with tunable morphology and chemical state on polycrystalline $\mathrm{Cu}$. These catalysts can lower the onset potential of $\mathrm{CO}_{2}$ reduction to ethylene by $350 \mathrm{mV}$ compared with electropolished $\mathrm{Cu}$, with a maximum faradaic selectivity of $>60 \%$ at $-0.9 \mathrm{~V}$ versus RHE. Here, using a combination of characterization techniques-including operando $\mathrm{X}$-ray absorption fine-structure spectroscopy (XAFS), scanning transmission electron microscopy (STEM) equipped with energy dispersive X-ray spectroscopy (EDS) - we gain insight into the catalysts in their working state and find that $\mathrm{Cu}^{+}$is the active species for reducing $\mathrm{CO}_{2}$ to ethylene. Through our results, we unravel the mechanism behind the improved activity and unique ethylene selectivity of oxide-derived $\mathrm{Cu}$ catalysts and lay out the design principles necessary for improved ethylene-selective $\mathrm{CO}_{2} \mathrm{RR}$ catalysts.

\section{Results}

Synthesis and characterization. To synthesize plasma-activated $\mathrm{Cu}$, electropolished polycrystalline $\mathrm{Cu}$ foils were treated in $\mathrm{O}_{2}$ and $\mathrm{H}_{2}$ plasmas of varying power and duration. Figure 1 presents scanning electron microscopy (SEM) images of the $\mathrm{Cu}$ films treated with $\mathrm{O}_{2}$ plasma at $20 \mathrm{~W}$ for 2 min (top row) and $100 \mathrm{~W}$ for 2 min (middle row) and 10 min (bottom row). By tuning the plasma conditions, the morphology of the surface and oxide thickness can be easily controlled. Growth of the $\mathrm{Cu}$ oxide begins at grain boundaries, forming micron-sized wires as shown in Fig. 1a. With increasing plasma time and power, the wires merged, forming a highly roughened surface, (c.f. Fig. 1b,e,i) and became highly porous with an observed $64 \%$ increase in the number of pores and $50 \%$ decrease in pore size (Supplementary Figs 1 and 2). Subsequently, the plasma-activated $\mathrm{Cu}$ samples were partially reduced in situ during $\mathrm{CO}_{2} \mathrm{RR}$, and the resulting surface morphology is shown in the last column of Fig. 1. For most samples, an increase in the porosity was observed. Interestingly, the sample oxidized at $100 \mathrm{~W}$ for $10 \mathrm{~min}$ showed the growth of hair-like nanoneedles after the reaction. To compare the effect of plasma reduction on the film morphology to the electrochemical reduction mentioned above, a $\mathrm{H}_{2}$ plasma was used ( $100 \mathrm{~W}$ for $10 \mathrm{~min}$ ), and is shown in Fig. 1g. The resulting structure was very similar to the electrochemically reduced sample (c.f. Fig. 1f), indicating that plasma reduction or electrochemical reduction of the $\mathrm{Cu}$ oxides results in a similar structure. SEM images for additional plasma treatments are shown in Supplementary Fig. 1 .

To gain further information on the structure and chemical state of the plasma-treated $\mathrm{Cu}$ films, cross-sections of the samples were measured using STEM combined with elemental mapping using EDS. Cross-sectional EDS maps of plasma-treated $\mathrm{Cu}$ samples before and after $\mathrm{CO}_{2} \mathrm{RR}$ are shown in Fig. 2 and Supplementary Fig. 3. After the $\mathrm{O}_{2}$ plasma treatment, the EDS maps show two well-defined oxide layers over the bulk metallic $\mathrm{Cu}$ film. Stoichiometric analysis using EDS data (Supplementary Table 1) resulted in $\mathrm{Cu}: \mathrm{O}$ ratios of $2.7: 1.0$ and 1.3:1.0 for the interlayer and upper layers, respectively, indicating that the interlayer is $\mathrm{Cu}_{2} \mathrm{O}$, while the upper layer is copper(II) oxide $(\mathrm{CuO})$. It is also apparent that at grain boundaries and crystallographic domains with the fastest oxide growth, a thick $1.5-\mu \mathrm{m} \mathrm{Cu}_{2} \mathrm{O}$ interlayer grows with a thinner $100 \mathrm{~nm} \mathrm{CuO}$ top layer, while in domains with slower oxide growth, the $\mathrm{CuO}$ layer is thicker at $260 \mathrm{~nm}$-as clearly shown in Fig. 2a. Figure $2 \mathrm{~g}$ shows the $100 \mathrm{~W} 2 \mathrm{~min}$ oxidized $\mathrm{Cu}$ with a subsequent $\mathrm{H}_{2}$ plasma treatment. A $100 \mathrm{~nm}$ layer at the surface is reduced entirely to metallic $\mathrm{Cu}$, with the $\mathrm{CuO}$ and $\mathrm{Cu}_{2} \mathrm{O}$ oxide layers being still observed subsurface. After $\mathrm{H}_{2}$ plasma treatment, the sample was exposed to air for more than a week before TEM sample preparation and analysis, and the native $\mathrm{Cu}$ oxide layer, measured to be $<3 \mathrm{~nm}$ thick, was insignificant compared with the thick oxide layers which formed from the plasma treatment and remained during the reaction. This indicates that the observed oxides in our samples before or after reaction are not simply due to surface oxidation in air during the ex situ sample transfer to the TEM. Figure 2c,f,h also shows EDS maps of these samples after $1 \mathrm{~h}$ of $\mathrm{CO}_{2} \mathrm{RR}$ at $-0.91 \mathrm{~V}$ versus RHE. Remarkably, after the reaction a single layer with $\mathrm{O}$ atom concentration ranging from 3 to 29 atomic \% remains with porous and oxygen-rich regions 


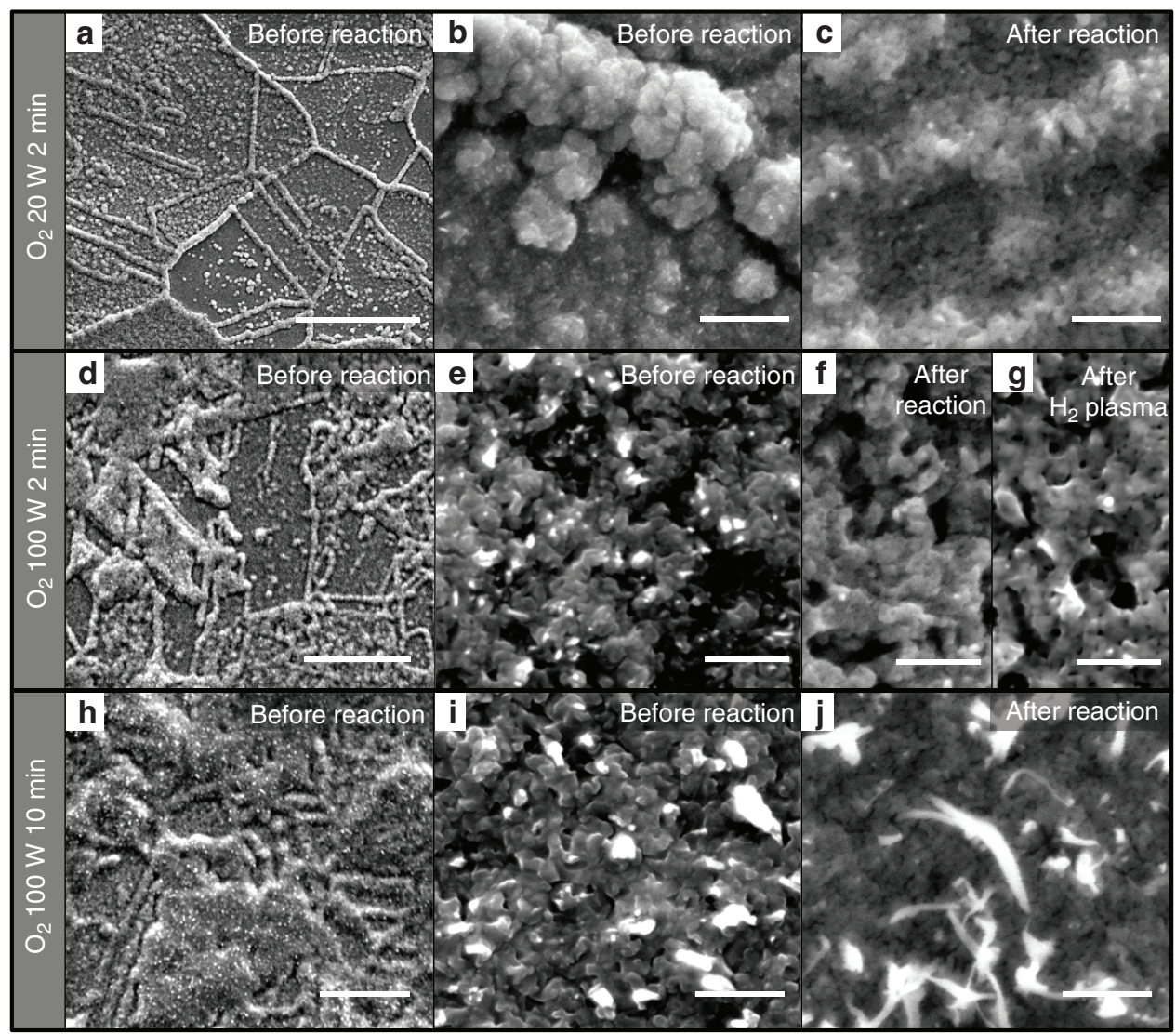

Figure 1 | Morphological characterization of plasma-treated $\mathbf{C u}$ foil electrodes. SEM images of $\mathrm{Cu}$ foils treated with $\mathrm{O}_{2}$ plasma for (a-c) $20 \mathrm{~W} 2$ min; (d-g) $100 \mathrm{~W} 2 \mathrm{~min}$; and (h-j) $100 \mathrm{~W} 10 \mathrm{~min}$. (a,b,d,e,h,i) The morphology of the as-prepared foils. (c,f,j) The morphology after the $\mathrm{CO}_{2} \mathrm{RR}$ reaction. $(\mathbf{g})$ The sample plasma treated with $\mathrm{O}_{2}$ at $100 \mathrm{~W}$ for 2 min after an additional $\mathrm{H}_{2}$ plasma treatment at $100 \mathrm{~W}$ for 10 min. Scale bars, (a) $10 \mu \mathrm{m} ;(\mathbf{b}, \mathbf{c}, \mathbf{e}-\mathbf{g}, \mathbf{i}, \mathbf{j}) 500 \mathrm{~nm}$; (d,h) $20 \mu \mathrm{m}$.
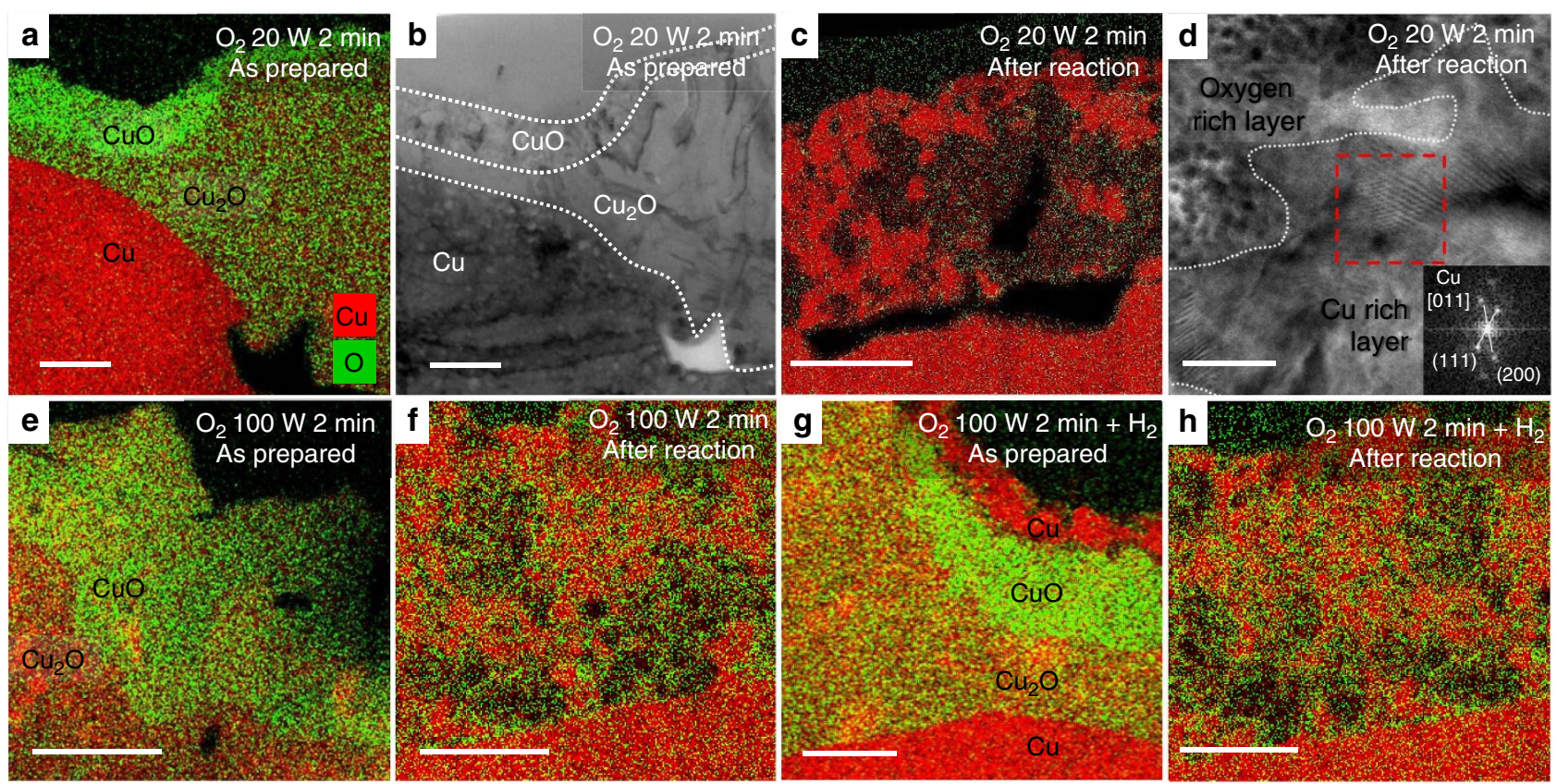

Figure 2 | Morphological and chemical analysis of plasma-activated $\mathbf{C u}$ foils. EDS elemental maps of $\mathrm{Cu}$ foils treated with $\mathrm{O}_{2}$ plasma for (a-d) $20 \mathrm{~W}$ $2 \mathrm{~min}$; (e-f) $100 \mathrm{~W} 2 \mathrm{~min}$; and (g-h) $100 \mathrm{~W} 2 \mathrm{~min}+\mathrm{H}_{2}$ plasma. The images labelled 'after reaction' were used as catalyst for $\mathrm{CO}_{2} \mathrm{RR}$ for $1 \mathrm{~h}$ at $-0.91 \mathrm{~V}$ versus RHE. (b,d) HRTEM and SAED analysis of the $\mathrm{O}_{2}$ plasma $20 \mathrm{~W} 2$ min treated sample before and after the reaction, respectively. Scale bars, (a-c) $300 \mathrm{~nm} ;(\mathbf{d}) 20 \mathrm{~nm} ;(\mathbf{e}-\mathbf{h}) 200 \mathrm{~nm}$. 

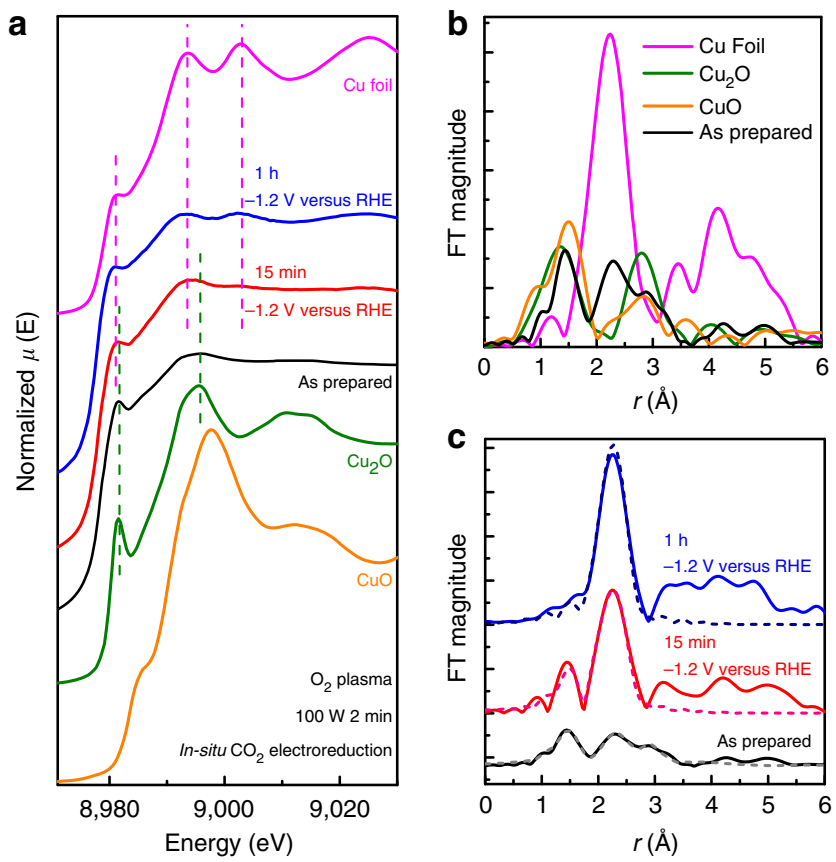

Figure 3 | Operando structural and chemical characterization during $\mathrm{CO}_{2}$ electroreduction. (a) XANES spectra of the $\mathrm{O}_{2} 100 \mathrm{~W} 2$ min treated sample measured under operando conditions in $0.1 \mathrm{M} \mathrm{KHCO}_{3}$ during the first 15 min and after $1 \mathrm{~h}$ of reaction at $-1.2 \mathrm{~V}$ versus RHE. Bulk $\mathrm{Cu}_{1} \mathrm{Cu}_{2} \mathrm{O}$ and $\mathrm{CuO}$ spectra are plotted as reference. (b) EXAFS spectrum of the asprepared sample plotted with references. (c) EXAFS spectra and fits (dashed lines) of the sample measured under operando conditions. Fourier transforms are $k^{2}$-weighted. Fit results are given in Supplementary Table 2.

observed. The $\mathrm{Cu}$ oxide species are present throughout the layer, indicating that the surface is rich in $\mathrm{Cu}^{+}$sites which remain stable on the surface and near surface layers during the reaction. This finding challenges the conventional assumption that only metallic $\mathrm{Cu}\left(\mathrm{Cu}^{0}\right)$ is the active species during $\mathrm{CO}_{2} \mathrm{RR}$ and indicates that $\mathrm{Cu}^{+}$plays a significant role in the unique reactivity of oxide-derived $\mathrm{Cu}$.

Figure 2b,d and Supplementary Fig. 4 show high-resolution TEM (HRTEM) and selected area electron diffraction (SAED) patterns of the $\mathrm{O}_{2} 20 \mathrm{~W} 2 \mathrm{~min}$ plasma-treated sample before and after the reaction. The diffraction analysis confirms that a $\mathrm{CuO}$ top layer and $\mathrm{Cu}_{2} \mathrm{O}$ interlayer exist before the reaction (Fig. 2b). After the reaction, the layer transforms into a mixture of $\mathrm{Cu}$-rich regions, which contain only $3.4 \pm 0.9 \%$ oxygen atoms, and oxygen-rich regions (Supplementary Fig. 4) with $19.5 \pm 2.6 \%$ oxygen atoms identified as $\mathrm{Cu}_{2} \mathrm{O}$. It is clear that the oxygen is depleted during the reaction, but the surface layer of the oxidized $\mathrm{Cu}$ films is still rich in oxygen even after $1 \mathrm{~h}$ of reaction. It is unlikely that the $\mathrm{Cu}$ oxides in the sample after reaction could be a result of air exposure, since the native oxide would be much thinner due to its slow growth rate at room temperature in air and would contain $\mathrm{Cu}$ (II) species, which are not observed here.

Operando X-ray absorption spectroscopy. To further investigate the changes in the structure of the oxide layer during $\mathrm{CO}_{2} \mathrm{RR}$ and gain insight into the chemical state of the active $\mathrm{Cu}$ species, operando X-ray absorption near-edge structure (XANES) and extended XAFS (EXAFS) were used. Figure 3 shows the $\mathrm{Cu}$ K-edge XANES and EXAFS spectra of the $\mathrm{O}_{2} 100 \mathrm{~W} 2 \mathrm{~min}$ plasma-treated $\mathrm{Cu}$ measured in fluorescence at small incidence angle (for enhanced surface sensitivity) during $\mathrm{CO}_{2} \mathrm{RR}$ at $-1.2 \mathrm{~V}$

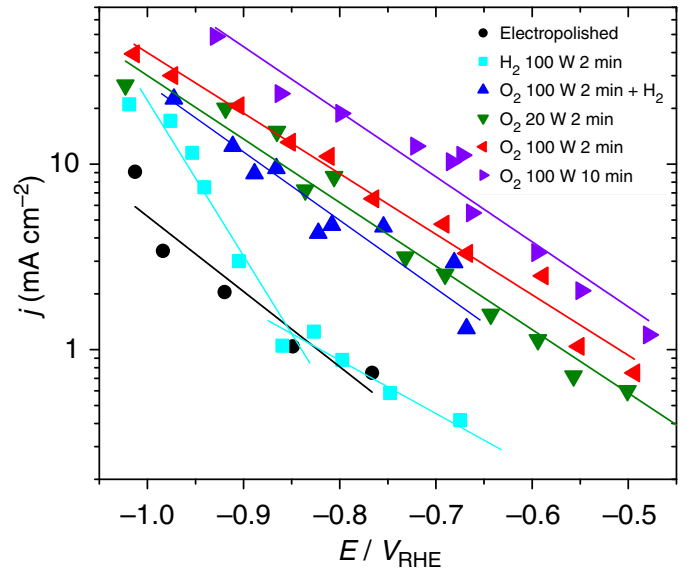

Figure 4 | Electrochemical activity during $\mathrm{CO}_{2}$ electroreduction.

Geometric reduction current density as a function of applied potential.

versus RHE. Although the thickness of the sample caused dampening of the XAFS signals due to self-absorption, the XANES spectrum of the as-prepared plasma-oxidized $\mathrm{Cu}$ shows the features of $\mathrm{Cu}_{2} \mathrm{O}$, in particular, the prominent shoulder at the edge marked with a green dashed line at $\sim 8,982 \mathrm{eV}$. The presence of metallic $\mathrm{Cu}$ and $\mathrm{Cu}$ oxide in the initial sample is also clear in the EXAFS data shown in Fig. 3b,c. During the first 15 min of reaction, a combination of $\mathrm{Cu}$ and $\mathrm{Cu}_{2} \mathrm{O}$ features are still present, and at $1 \mathrm{~h}$, only metallic $\mathrm{Cu}$ features are discernable. Although an oxygen content of $\sim 25-28 \%$ is still present in the surface layer of the catalyst after $1 \mathrm{~h}$ of reaction according to STEM-EDS, XAFS probes further into the bulk, and when the films are partially reduced, the XAFS signals become dominated by the signal of the metallic $\mathrm{Cu}$ underlayer. Nevertheless, we have shown here unquestionably that for our plasma-oxidized $\mathrm{Cu}$ catalyst, $\mathrm{Cu}_{2} \mathrm{O}$ species are present and can participate in the reaction. It is clear that significant changes occur in the bulk of the $\mathrm{Cu}$ oxide layer during the first $15 \mathrm{~min}$ of reaction in which the initial $\mathrm{CuO}$ and $\mathrm{Cu}_{2} \mathrm{O}$ layers are reconstructed and some of the oxygen is depleted. After this initial change, it is likely that the $\mathrm{Cu}_{2} \mathrm{O}$ species remain relatively stable in the surface layer, since the activity and selectivity measured after $10 \mathrm{~min}$ and $1 \mathrm{~h}$ are unchanged for all the oxidized samples, see Supplementary Fig. 5. Furthermore, the reactivity of the $\mathrm{O}_{2} 20 \mathrm{~W} 2 \mathrm{~min}$ sample was observed to be stable over the course of $5 \mathrm{~h}$, suggesting there is no significant change on the active phase during this time (Supplementary Fig. 6). Therefore, it is likely that $\mathrm{Cu}^{+}$species can be supplied to the surface from the thick initial oxide surface and subsurface layers during the reaction to maintain the reactivity of these catalysts over time.

$\mathrm{CO}_{2}$ electroreduction performance. The catalytic activity and selectivity of the plasma-activated copper foils were studied by performing bulk electrolysis in $0.1 \mathrm{M}$ potassium bicarbonate $\left(\mathrm{KHCO}_{3}\right)$ at a constant potential and analysing the reaction products via chromatographic techniques. Figure 4 shows the geometric current density as a function of applied potential. The plasma treatment has a clear effect on the activity of $\mathrm{Cu}$ towards $\mathrm{CO}_{2} \mathrm{RR}$ which can partially be attributed to the surface roughness. In general, longer and higher power $\mathrm{O}_{2}$ plasma treatment increases the roughness factor (Table 1), which is an estimate of the active surface area derived by measuring the double layer capacity and normalizing by the electropolished foil (Supplementary Table 3; Supplementary Fig. 7). However, roughness effects alone cannot explain all of our experimental 
findings satisfactorily. In fact, the initial oxidation state of the sample also affects the current density. This is particularly evident when we compare the catalytic activity of the $\mathrm{O}_{2} 100 \mathrm{~W} 2 \mathrm{~min}$ and $\mathrm{O}_{2} 100 \mathrm{~W} 2 \mathrm{~min}+\mathrm{H}_{2}$ plasma-treated $\mathrm{Cu}$. Although both samples have a similar surface roughness, as shown in Table 1, their catalytic activity is significantly different. The $\mathrm{H}_{2}$ plasma treatment on the oxidized sample reduces the activity by about two times compared with the oxidized sample without $\mathrm{H}_{2}$ treatment. The $\mathrm{H}_{2}$ plasma treatment depletes the oxide species available initially in the sample, as shown in Fig. $2 \mathrm{~g}$, while having minimal effect on the surface roughness. This result is an indication that the $\mathrm{Cu}$ oxide species are critical for improved current density. As demonstrated by our STEM-EDS data, even after $1 \mathrm{~h}$ of $\mathrm{CO}_{2} \mathrm{RR}$, patches of $\mathrm{Cu}_{2} \mathrm{O}$ are still observed near the sample surface.

Figure 5 shows the faradaic selectivity of the $\mathrm{CO}_{2} \mathrm{RR}$ products for the plasma-activated $\mathrm{Cu}$ samples as a function of applied potential. The plasma treatments not only affect the activity of copper, but more importantly, they also have a remarkable effect on selectivity. The selectivity change is most drastic on the $\mathrm{O}_{2}$ treated samples: on one hand, this treatment clearly suppresses methane formation (Fig. 5c), while on the other hand, it enhances the formation of the other products of $\mathrm{CO}_{2} \mathrm{RR}(\mathrm{CO}$, formate and

\section{Table 1 | Roughness factors estimated through capacitance measurements.}

\section{Sample}

Roughness factor

Electropolished
$\mathrm{H}_{2} 100 \mathrm{~W} 2 \mathrm{~min}$
$\mathrm{O}_{2} 20 \mathrm{~W} 2 \mathrm{~min}$
$\mathrm{O}_{2} 100 \mathrm{~W} 2 \mathrm{~min}$
$\mathrm{O}_{2} 100 \mathrm{~W} 2 \mathrm{~min}+\mathrm{H}_{2}$
$\mathrm{O}_{2} 100 \mathrm{~W} 10 \mathrm{~min}$

ethylene). Consistent with results from Kanan and co-workers ${ }^{22}$, we observe that the onset potential towards $\mathrm{CO}$ and formate $\left(\mathrm{HCOO}^{-}\right)$is shifted to lower overpotentials. Furthermore, for our plasma-oxidized $\mathrm{Cu}$, the selectivity towards $\mathrm{CO}$ reaches a maximum of $60 \%$ at $-0.5 \mathrm{~V}$ versus $\mathrm{RHE}$, which is three times higher than for electropolished $\mathrm{Cu}$ foil. In our study, the onset of ethylene production is also shifted from approximately $-0.85 \mathrm{~V}$ versus RHE for metallic $\mathrm{Cu}$ foils to as low as $-0.5 \mathrm{~V}$ versus RHE for the most oxidized $\mathrm{Cu}$ foils. In addition, we observe a remarkably high selectivity towards ethylene, reaching $60 \%$ at $-0.9 \mathrm{~V}$ versus RHE for the $\mathrm{O}_{2} 20 \mathrm{~W} 2 \mathrm{~min}$ plasma-treated sample. This value is higher than other oxide-derived $\mathrm{Cu}$ catalysts synthesized from thermal oxidation ${ }^{22}$, which show $<10 \%$ ethylene efficiency at these potentials, or from electrodepositon of $\mathrm{Cu}_{2} \mathrm{O}^{21,23,24}$. In addition, the most oxidized foils in this study also produce trace amounts of ethanol (Supplementary Fig. 8). Interestingly, the $100 \mathrm{~W} \mathrm{O}_{2}$ plasma-treated samples, which have been exposed to a stronger oxygen plasma treatment and are characterized by the highest roughness factors, also produce trace amounts of ethane, but nonetheless exhibit lower $\mathrm{C}_{2} \mathrm{H}_{4}$ selectivities. These results indicate that there is an optimal oxidation treatment to favour ethylene formation, in agreement with results from Ren et $a l^{21}$. We hypothesize that this trend could be related to mass diffusion limiting ethylene formation on the most roughened surfaces where high geometric currents are achieved. This is also consistent with our observation that at high overpotentials - at which high geometric current densities are also achieved-ethylene selectivity is suppressed.

To confirm that the selectivity trend for the oxidized samples is due to the oxidation state, not the surface roughness, we can compare the $\mathrm{O}_{2} 100 \mathrm{~W} 2 \mathrm{~min}$ treated sample with the same sample which was exposed to an identical $\mathrm{O}_{2}$ plasma treatment plus $\mathrm{H}_{2}$ plasma. Despite their similar roughness (Table 1), their selectivity is drastically different. On both samples, methane formation is suppressed, however on the former sample, which
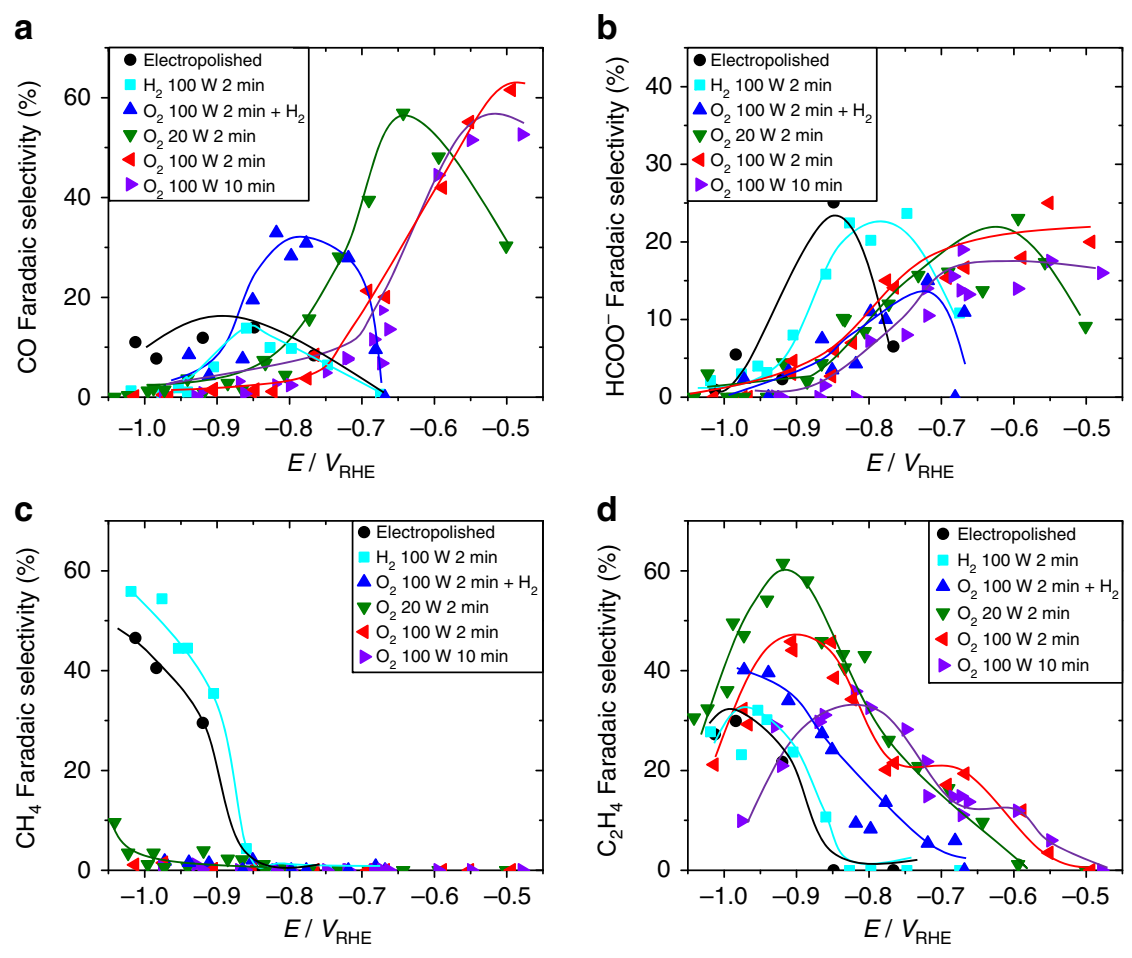

Figure 5 | Faradaic selectivities of the main $\mathbf{C O}_{\mathbf{2}} \mathbf{R R}$ products. Data were acquired after 60 min of $\mathrm{CO}_{2}$ electrolysis at a constant potential in $\mathrm{CO}_{2}$ saturated $0.1 \mathrm{M} \mathrm{KHCO}_{3}$. (a) $\mathrm{CO}$, (b) formate, (c) $\mathrm{CH}_{4}$ (d) $\mathrm{C}_{2} \mathrm{H}_{4}$. Solid lines are guides for the eye. The remaining selectivity is due to $\mathrm{H}_{2}$, which is shown in Supplementary Fig. 8. 


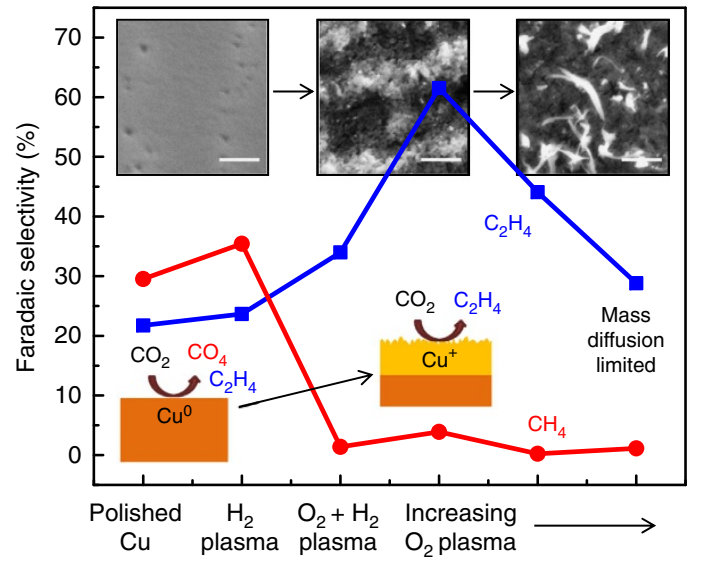

Figure 6 | Summary of hydrocarbon selectivity of plasma-treated $\mathrm{Cu}$

foils. From left to right, the insets show SEM images of the low surface area $\mathrm{H}_{2}$ plasma-treated metallic Cu foil, the $\mathrm{O}_{2} 20 \mathrm{~W} 2$ min plasma-treated $\mathrm{Cu}$ foil with optimal ethylene selectivity, and the high surface area nanoneedles on the $\mathrm{O}_{2} 100 \mathrm{~W} 10 \mathrm{~min}$ oxidized sample after the reaction ( $500 \mathrm{~nm}$ scale bars).

was only treated with $\mathrm{O}_{2}$ plasma, the onset potential for the formation of $\mathrm{CO}, \mathrm{HCOO}^{-}$and $\mathrm{C}_{2} \mathrm{H}_{4}$ is clearly shifted to less negative potentials. The main difference between these two samples is the availability of $\mathrm{Cu}^{+}$sites in their initial state. Thus, by depleting the $\mathrm{Cu}^{+}$sites using the $\mathrm{H}_{2}$ plasma, we have reduced the number of active sites available for $\mathrm{C}_{2} \mathrm{H}_{4}$ formation, and therefore altered the selectivity.

We also observed that the $\mathrm{H}_{2} 100 \mathrm{~W} 2$ min plasma-treated sample, which has a similar roughness to the electropolished $\mathrm{Cu}$ foil, has an improved catalytic performance towards $\mathrm{CO}_{2} \mathrm{RR}$ compared with the polished foil. The $\mathrm{H}_{2}$ plasma-treated sample exhibits an earlier onset potential for formate production and a higher faradaic selectivity towards methane. An explanation for this effect could be improved $\mathrm{CO}_{2}$ reduction on defect sites generated by the plasma treatment, as shown in Supplementary Fig. 1. Another possible mechanism could be cleaning of contaminants or the native oxide from the $\mathrm{Cu}$ surface by the $\mathrm{H}_{2}$ plasma, which may improve the $\mathrm{CO}_{2} \mathrm{RR}$ performance in comparison to the electropolished sample. XPS shows that the small adventitious carbon $1 \mathrm{~s}$ peak present on the electropolished foil is diminished after the $\mathrm{H}_{2}$ plasma treatment, although the oxidation state of the surface of the foil is not changed (Supplementary Fig. 9).

\section{Discussion}

Figure 6 shows a summary of the hydrocarbon selectivity as a function of the plasma treatment of the $\mathrm{Cu}$ foils. Two competing effects are controlling the reactivity of the plasma-treated Cu foils: the surface roughness and the oxidation state of the surface layer. As described above, after oxidizing the surface layer with $\mathrm{O}_{2}$ plasma, we see an almost complete suppression of methane formation. As the foils are more oxidized, the surface roughness increases, and there is a drop in the ethylene selectivity, likely due to mass diffusion limitations.

Previous studies have proposed that the catalytic behaviour of such oxygen-derived $\mathrm{Cu}$ catalysts can be attributed to a roughness effect or to the presence of strongly binding defect sites such as grain boundaries. Recent work in Verdaguer-Casadevall et al. ${ }^{25}$ have shown that CO-binding energy on oxide-derived $\mathrm{Cu}$ is higher than on metallic copper. This high-binding energy could explain the early onset potential for $\mathrm{CO}_{2} \mathrm{RR}$, but does not explain why subsequent $\mathrm{H}_{2}$ plasma treatment would suppress the ethylene selectivity of the $100 \mathrm{~W} 2 \mathrm{~min}$ oxidized sample in our study.
Another proposed mechanism for the behaviour of oxidederived $\mathrm{CO}_{2} \mathrm{RR}$ catalysts is a $\mathrm{pH}$ effect. It is expected that during the catalytic reaction on these rough surfaces there is a significant rise in the local $\mathrm{pH}$, suppressing the $\mathrm{pH}$-dependent $\mathrm{CO}$ protonation that leads to methane formation ${ }^{41,42}$. The $\mathrm{pH}$ independent pathway via $\mathrm{CO}$ dimerization, however, is not affected, resulting in high ethylene selectivities $28,43,44$. Consistently, all samples with some initial oxidation treatment (rough surfaces) exhibit suppression of methane, as shown in Fig. 6, which may be attributed to the $\mathrm{pH}$ effect. However, the lower onset potential for ethylene production observed in the oxygen-treated samples (Fig. 5d) cannot be attributed to a local $\mathrm{pH}$ effect. In fact we observed that that the increasing oxidation treatment leads to a decrease in the overpotential for $\mathrm{C}_{2} \mathrm{H}_{4}$ production, indicating that high activity for ethylene can be related to the oxidation-reduction treatment and not to a local $\mathrm{pH}$ effect.

By comparing the catalytic performance of $\mathrm{O}_{2}$ plasma $100 \mathrm{~W}$ $2 \mathrm{~min}+\mathrm{H}_{2}$ and $\mathrm{O}_{2}$ plasma $100 \mathrm{~W} 2 \mathrm{~min} \mathrm{Cu}$, we have demonstrated that purely a roughness effect cannot explain the reactivity trends of our plasma-activated oxide-derived $\mathrm{Cu}$ catalysts, since these catalysts with nearly the same roughness, but different oxide content have significantly different reactivity and selectivity. In addition, while the high local $\mathrm{pH}$ could explain the suppression of $\mathrm{CH}_{4}$, it cannot explain the earlier onset potential for $\mathrm{CO}_{2} \mathrm{RR}$. Since surface roughness and $\mathrm{pH}$ effects cannot fully explain the reactivity of our plasma-activated $\mathrm{Cu}$, it is clear that another mechanism is also involved in controlling the reactivity. Based on our STEM-EDS and operando XAFS measurement we conclude that, contrary to common belief, $\mathrm{Cu}^{+}$species are stable under reaction conditions and play a determining role in the reactivity of oxide-derived $\mathrm{Cu}$. These species may interact with negatively charged $\mathrm{CO}_{2}$ reduction intermediates which may play an important role in determining selectivity. ${ }^{41}$

The mechanism behind the stability of $\mathrm{Cu}^{+}$species under the thermodynamically unfavourable conditions of $\mathrm{CO}_{2} \mathrm{RR}$ is still under investigation, however, several mechanisms may explain this phenomenon. One possibility is that the highly roughened surfaces with low-coordinated sites which are formed after $\mathrm{O}_{2}$ plasma treatment may bind more strongly to oxygen, helping to stabilize oxides during the reaction. Strain in the surface caused by the oxidation and reduction of the surface may also cause strong oxygen binding. The highly porous nature of the films formed might also serve as favourable oxygen reservoir. Another possibility is that the high local $\mathrm{pH}$ could help to stabilize $\mathrm{Cu}^{+}$by negatively shifting the overpotential for $\mathrm{Cu}_{2} \mathrm{O}$ reduction. Recent studies of nanostructured tin oxide catalysts for $\mathrm{CO}_{2}$ electroreduction have also suggested that oxide species are stable during the reaction and play a controlling role in their selectivity. Sn oxides and not metallic Sn were shown to be the active species for $\mathrm{CO}_{2}$ reduction to formic acid and are metastable during the reaction at reducing potentials, even though the oxides are thermodynamically unstable under these conditions ${ }^{45-47}$. While similar stability of $\mathrm{Cu}^{+}$has been suggested for oxide-derived $\mathrm{Cu}$ catalysts $^{23,31,48}$, we provide here the first direct evidence that $\mathrm{Cu}^{+}$species are stable during $\mathrm{CO}_{2} \mathrm{RR}$ and are key for controlling selectivity.

In summary, we have synthesized superior oxygen-derived $\mathrm{Cu}$ catalysts using plasma treatments and used a synergistic combination of advanced ex situ, in situ and operando techniques to reveal the key mechanisms behind the improved performance of oxide-derived copper catalysts. Plasma treatment was found to be a facile method to rapidly oxidize $\mathrm{Cu}$ foils, which resulted in stable oxide layers with a unique surface structure. These plasma-oxidized catalysts achieve lower onset potentials for $\mathrm{CO}$, formate and ethylene, as well as outstanding ethylene selectivity 
of $60 \%$ at $-0.9 \mathrm{~V}$ versus RHE. In addition, using STEM-EDS and operando XAFS, we have found that the oxides in the surface layer are surprisingly stable against reduction, with a significant amount of oxide species and dissolved oxygen remaining after $1 \mathrm{~h}$ of reaction at relatively high potentials $(-0.91 \mathrm{~V}$ versus RHE). Furthermore, ethylene synthesis and methane suppression are due to the presence of these oxides. It is expected that the fundamental understanding extracted from our experimental study could aid the further design and optimization of oxidederived $\mathrm{Cu}$ catalysts.

\section{Methods}

Catalyst synthesis. All $\mathrm{Cu}$ foils were initially electropolished in $85 \%$ phosphoric acid at $3 \mathrm{~V}$ versus a titanium foil, then thoroughly rinsed with ultra-pure water and dried with nitrogen. Plasma treatments were performed in 400 mtorr of $\mathrm{H}_{2}$ or $\mathrm{O}_{2}$ for the indicated plasma power and time. For the $\mathrm{O}_{2} 100 \mathrm{~W} 2 \mathrm{~min}+\mathrm{H}_{2}$-treated sample, $100 \mathrm{~W} 10 \mathrm{~min}$ of $\mathrm{H}_{2}$ plasma was used.

\section{Electron microscopy. SEM images were obtained using a Quanta 200 FEG} microscope from FEI with a field emitter as electron source. A secondary electron (Everhart-Thornley) detector was used for the image acquisition. An electron acceleration voltage of $10 \mathrm{kV}$ and a working distance of $10 \mathrm{~mm}$ were chosen for the measurements. TEM cross-section samples were prepared using a FEI Helios 600 Dual Beam Focused Ion Beam (FIB) at the Center for Functional Nanomaterials (CFN) at Brookhaven National Laboratory (BNL). The FIB sectioning was performed at $30 \mathrm{keV}$ with final milling at $5 \mathrm{KeV}$. Spatially resolved elemental maps were acquired using a FEI Titan TEM/STEM microscope with ChemiSTEM technology (X-FEG and SuperX with four windowless silicon drift EDS detectors) operated at $200 \mathrm{kV}$, at the National Center for Electron Microscopy (NCEM), Molecular Foundry at Lawrence Berkeley National Laboratory (LBL). A Hitachi 9500 TEM at the Nanoscale Fabrication and Characterization Facility (NFCF), University of Pittsburgh operated at $200 \mathrm{keV}$ was used to acquire HRTEM images and SAED patterns.

X-ray absorption spectroscopy. XANES and EXAFS spectra were measured at beamline 2-2 of the Stanford Synchrotron Light Source. A home-built operando electrochemical cell was used, with a platinum foil counter electrode and silver/ silver chloride $(\mathrm{Ag} / \mathrm{AgCl})$ reference electrode. The samples were mounted behind an X-ray kapton window with $1 \mathrm{~mm}$ of electrolyte between the sample and window. The electrolyte $\left(0.1 \mathrm{M} \mathrm{KHCO}_{3}\right)$ was circulated between the cell and a reservoir in which $\mathrm{CO}_{2}$ was continuously bubbled. Measurements were performed in fluorescence at small incidence angle using a passivated implanted planar silicon (PIPS) detector. The acquisition of each spectrum took $15 \mathrm{~min}$, and they were acquired during the first $15 \mathrm{~min}$ and after $1 \mathrm{~h}$ of reaction.

Data analysis was performed using the Athena and Artemis software. The FEFF8 code was used to simulate $\mathrm{Cu}, \mathrm{Cu}_{2} \mathrm{O}$ and $\mathrm{CuO}$ spectra for EXAFS fitting Further details are given in the Supplementary Table 2.

Electrochemical measurements. Electrochemical measurements were carried out in a custom made two compartment cell, separated by a Nafion membrane. The glassware was cleaned in a 'nochromix' bath and afterwards in concentrated $\mathrm{HNO}_{3}$ for $1 \mathrm{~h}$, respectively, rinsed and sonicated with ultra-pure water several times. The working compartment was filled with $120 \mathrm{ml} 0.1 \mathrm{M} \mathrm{KHCO}_{3}$ (Sigma-Aldrich $\geq 99.95 \%$ ). Before and during the electrochemical reaction the cell was purged continuously with $\mathrm{CO}_{2}\left(30 \mathrm{ml} \mathrm{min}^{-1}\right)$, reaching a stable $\mathrm{pH}$ value of 6.8 .

A platinum mesh 100 (Sigma-Aldrich 99.9\%) was used as counter electrode and a leak-free $\mathrm{Ag} / \mathrm{AgCl}$ electrode as reference electrode (Hugo Sachs Elektronik Harvard apparatus $\mathrm{GmbH}$ ). The plasma-treated $\mathrm{Cu}$ foils were used as working electrode and contacted by a gold clamp. Every measurement was started with a linear voltammetric sweep, performed with a scan rate of $-5 \mathrm{mV} \mathrm{s}{ }^{-1}$ between $E=+0.05 \mathrm{~V} / \mathrm{RHE}$ and the working potential (between $-0.45 \mathrm{~V}$ and $-1.0 \mathrm{~V} /$ $\mathrm{RHE}$ ) followed by a chronoamperometric step for $60 \mathrm{~min}$. All reported potentials are corrected for Ohmic drop determined by electrochemical impedance spectroscopy.

Product analysis. After 10 and $60 \mathrm{~min}$ of bulk electrolysis at constant potential, a sample of the gas was analysed by gas chromatography (Shimadzu GC 2016) to determine the production rate and faradaic selectivity of the gaseous products. In addition, an aliquot of the electrolyte was analysed by a high-performance liquid chromatograph (Agilent 1200 series).

Data availability. The data supporting the findings of this study are available within the article and its Supplementary information files. All other relevant source data are available from the corresponding author upon request.

\section{References}

1. Hori, Y. in Modern Aspects of Electrochemistry Vol. 42 (eds Vayenas, C. G., White, R. E. \& Gambao-Aldaco, M. E.) 89-189 (Springer, 2008).

2. Kuhl, K. P., Cave, E. R., Abram, D. N. \& Jaramillo, T. F. New insights into the electrochemical reduction of carbon dioxide on metallic copper surfaces. Energy Eviron. Sci. 5, 7050-7059 (2012).

3. Hori, Y., Kikuchi, K. \& Suzuki, S. Production of $\mathrm{CO}$ and $\mathrm{CH}_{4}$ in electrochemical reduction of $\mathrm{CO}_{2}$ at metal electrodes in aqueous hydrogencarbonate solution. Chem. Lett. 14, 1695-1698 (1985).

4. Hori, Y., Murata, A. \& Takahashi, R. Formation of hydrocarbons in the electrochemical reduction of carbon dioxide at a copper electrode in aqueous solution. J. Chem. Soc. Farad. Trans. 1 85, 2309-2326 (1989).

5. Peterson, A. A. \& Nørskov, J. K. Activity descriptors for $\mathrm{CO}_{2}$ electroreduction to methane on transition-metal catalysts. J. Phys. Chem. Lett. 3, 251-258 (2012).

6. Hansen, H. A., Varley, J. B., Peterson, A. A. \& Nørskov, J. K. Understanding trends in the electrocatalytic activity of metals and enzymes for $\mathrm{CO}_{2}$ reduction to CO. J. Phys. Chem. Lett. 4, 388-392 (2013).

7. Peterson, A. A., Abild-Pedersen, F., Studt, F., Rossmeisl, J. \& Nørskov, J. K. How copper catalyzes the electroreduction of carbon dioxide into hydrocarbon fuels. Energy Eviron. Sci. 3, 1311-1315 (2010).

8. Zhang, Y.-J., Sethuraman, V., Michalsky, R. \& Peterson, A. A. Competition between $\mathrm{CO}_{2}$ reduction and $\mathrm{H}_{2}$ evolution on transition-metal electrocatalysts. ACS Catal. 4, 3742-3748 (2014).

9. Reske, R., Mistry, H., Behafarid, F., Roldan Cuenya, B. \& Strasser, P. Particle size effects in the catalytic electroreduction of $\mathrm{CO}_{2}$ on $\mathrm{Cu}$ nanoparticles. J. Am Chem. Soc. 136, 6978-6986 (2014).

10. Mistry, H. et al. Exceptional size-dependent activity enhancement in the electroreduction of $\mathrm{CO}_{2}$ over $\mathrm{Au}$ nanoparticles. J. Am. Chem. Soc. 136, 16473-16476 (2014).

11. Mistry, H. et al. Tuning catalytic selectivity at the mesoscale via interparticle interactions. ACS Catal. 6, 1075-1080 (2015).

12. Tang, W. et al. The importance of surface morphology in controlling the selectivity of polycrystalline copper for $\mathrm{CO}_{2}$ electroreduction. Phys. Chem. Chem. Phys. 14, 76-81 (2012).

13. Baturina, O. A. et al. $\mathrm{CO}_{2}$ electroreduction to hydrocarbons on carbonsupported Cu nanoparticles. ACS Catal. 4, 3682-3695 (2014).

14. Manthiram, K., Beberwyck, B. J. \& Alivisatos, A. P. Enhanced electrochemical methanation of carbon dioxide with a dispersible nanoscale copper catalyst. J. Am. Chem. Soc. 136, 13319-13325 (2014).

15. Chen, C. S. et al. Stable and selective electrochemical reduction of carbon dioxide to ethylene on copper mesocrystals. Catal. Sci. Technol. 5, 161-168 (2015).

16. Roberts, F. S., Kuhl, K. P. \& Nilsson, A. High selectivity for ethylene from carbon dioxide reduction over copper nanocube electrocatalysts. Angew. Chem Int. Ed. Engl. 127, 5268-5271 (2015).

17. Sen, S., Liu, D. \& Palmore, G. T. R. Electrochemical reduction of $\mathrm{CO}_{2}$ at copper nanofoams. ACS Catal. 4, 3091-3095 (2014).

18. Zhu, W. et al. Active and selective conversion of $\mathrm{CO}_{2}$ to $\mathrm{CO}$ on ultrathin $\mathrm{Au}$ nanowires. J. Am. Chem. Soc. 136, 16132-16135 (2014).

19. Lu, Q., Rosen, J. \& Jiao, F. Nanostructured metallic electrocatalysts for carbon dioxide reduction. ChemCatChem 7, 38-47 (2015).

20. Mistry, H., Varela, A. S., Kuehl, S., Strasser, P. \& Roldan Cuenya, B. Nanostructured electrocatalysts with tunable activity and selectivity. Nat. Rev Mater. 1, 16009 (2016)

21. Ren, D. et al. Selective electrochemical reduction of carbon dioxide to ethylene and ethanol on copper (I) oxide catalysts. ACS Catal. 5, 2814-2821 (2015).

22. Li, C. W. \& Kanan, M. W. $\mathrm{CO}_{2}$ reduction at low overpotential on $\mathrm{Cu}$ electrodes resulting from the reduction of thick $\mathrm{Cu}_{2} \mathrm{O}$ films. J. Am. Chem. Soc. 134, 7231-7234 (2012).

23. Kim, D. et al. Insights into an autonomously formed oxygen-evacuated $\mathrm{Cu}_{2} \mathrm{O}$ electrode for the selective production of $\mathrm{C}_{2} \mathrm{H}_{4}$ from $\mathrm{CO}_{2}$. Phys. Chem. Chem. Phys. 17, 824-830 (2015).

24. Kas, R. et al. Electrochemical $\mathrm{CO}_{2}$ reduction on $\mathrm{Cu}_{2} \mathrm{O}$-derived copper nanoparticles: controlling the catalytic selectivity of hydrocarbons. Phys. Chem Chem. Phys. 16, 12194-12201 (2014)

25. Verdaguer-Casadevall, A. et al. Probing the active surface sites for CO reduction on oxide-derived copper electrocatalysts. J. Am. Chem. Soc. 137, 9808-9811 (2015).

26. Li, C. W., Ciston, J. \& Kanan, M. W. Electroreduction of carbon monoxide to liquid fuel on oxide-derived nanocrystalline copper. Nature 508, 504-507 (2014).

27. Gupta, N., Gattrell, M. \& MacDougall, B. Calculation for the cathode surface concentrations in the electrochemical reduction of $\mathrm{CO}_{2}$ in $\mathrm{KHCO}_{3}$ solutions. J. Appl. Electrochem. 36, 161-172 (2006).

28. Varela, A. S., Kroschel, M., Reier, T. \& Strasser, P. Controlling the selectivity of $\mathrm{CO}_{2}$ electroreduction on copper: the effect of the electrolyte concentration and the importance of the local pH. Catal. Today 260, 8-13 (2016) 
29. Kas, R., Kortlever, R., Yılmaz, H., Koper, M. \& Mul, G. Manipulating the hydrocarbon selectivity of copper nanoparticles in $\mathrm{CO}_{2}$ electroreduction by process conditions. ChemElectroChem 2, 354-358 (2015).

30. Schouten, K. J. P., Gallent, E. P. \& Koper, M. T. The influence of pH on the reduction of $\mathrm{CO}$ and $\mathrm{CO}_{2}$ to hydrocarbons on copper electrodes. J. Electroanal. Chem. 716, 53-57 (2014).

31. Lee, S. \& Lee, J. Electrode build-up of reducible metal composites toward achievable electrochemical conversion of carbon dioxide. ChemSusChem 9, 333-344 (2015).

32. Shibata, H., Moulijn, J. A. \& Mul, G. Enabling electrocatalytic Fischer-Tropsch synthesis from carbon dioxide over copper-based electrodes. Catal. Lett. 123, 186-192 (2008).

33. Zhang, Y.-J. \& Peterson, A. A. Oxygen-induced changes to selectivitydetermining steps in electrocatalytic $\mathrm{CO}_{2}$ reduction. Phys. Chem. Chem. Phys. 17, 4505-4515 (2015).

34. Nie, X., Griffin, G. L., Janik, M. J. \& Asthagiri, A. Surface phases of $\mathrm{Cu}_{2} \mathrm{O}(111)$ under $\mathrm{CO}_{2}$ electrochemical reduction conditions. Catal. Commun. 52, 88-91 (2014).

35. Le, M. et al. Electrochemical reduction of $\mathrm{CO}_{2}$ to $\mathrm{CH}_{3} \mathrm{OH}$ at copper oxide surfaces. J. Electrochem. Soc. 158, E45-E49 (2011).

36. Roldan Cuenya, B. Metal nanoparticle catalysts beginning to shape-up. Acc. Chem. Res. 46, 1682-1691 (2012).

37. Menard, L. D., Xu, F., Nuzzo, R. G. \& Yang, J. C. Preparation of $\mathrm{TiO}_{2}-$ supported $\mathrm{Au}$ nanoparticle catalysts from a $\mathrm{Au}_{13}$ cluster precursor: ligand removal using ozone exposure versus a rapid thermal treatment. J. Catal. 243, 64-73 (2006).

38. Zou, J.-J., Liu, C.-J. \& Zhang, Y.-P. Control of the metal-support interface of $\mathrm{NiO}$-loaded photocatalysts via cold plasma treatment. Langmuir 22, 2334-2339 (2006).

39. Ono, L. K. \& Roldan Cuenya, B. Formation and thermal stability of $\mathrm{Au}_{2} \mathrm{O}_{3}$ on gold nanoparticles: size and support effects. J. Phys. Chem. C 112, 4676-4686 (2008).

40. Zhou, Y. et al. Dopant-induced electronic structure modification of HOPG surfaces: implications for high activity fuel cell catalysts. J. Phys. Chem. C 114, 506-515 (2009)

41. Kortlever, R., Shen, J., Schouten, K. J. P., Calle-Vallejo, F. \& Koper, M. T. Catalysts and reaction pathways for the electrochemical reduction of carbon dioxide. J. Phys. Chem. Lett. 6, 4073-4082 (2015).

42. Nie, X., Esopi, M. R., Janik, M. J. \& Asthagiri, A. Selectivity of $\mathrm{CO}_{2}$ reduction on copper electrodes: the role of the kinetics of elementary steps. Angew. Chem. Int. Ed. Engl. 52, 2459-2462 (2013)

43. Calle-Vallejo, F. \& Koper, M. Theoretical considerations on the electroreduction of $\mathrm{CO}$ to $\mathrm{C} 2$ species on $\mathrm{Cu}(100)$ electrodes. Angew. Chem. Int. Ed. Engl. 125, 7423-7426 (2013)

44. Montoya, J. H., Shi, C., Chan, K. \& Norskov, J. K. Theoretical insights into a $\mathrm{CO}$ dimerization mechanism in $\mathrm{CO}_{2}$ electroreduction. J. Phys. Chem. Lett. 6, 2032-2037 (2015)

45. Dutta, A., Kuzume, A., Rahaman, M., Vesztergom, S. \& Broekmann, P. Monitoring the chemical state of catalysts for $\mathrm{CO}_{2}$ electroreduction: an in operando study. ACS Catal. 5, 7498-7502 (2015).

46. Baruch, M. F., Pander, III J. E., White, J. L. \& Bocarsly, A. B. Mechanistic insights into the reduction of $\mathrm{CO}_{2}$ on tin electrodes using in situ ATR-IR spectroscopy. ACS Catal. 5, 3148-3156 (2015).

47. Chen, Y. \& Kanan, M. W. Tin oxide dependence of the $\mathrm{CO}_{2}$ reduction efficiency on tin electrodes and enhanced activity for tin/tin oxide thin-film catalysts. J. Am. Chem. Soc. 134, 1986-1989 (2012).
48. Lee, S., Kim, D. \& Lee, J. Electrocatalytic production of C3-C4 compounds by conversion of $\mathrm{CO}_{2}$ on a chloride-induced bi-phasic $\mathrm{Cu}_{2} \mathrm{O}-\mathrm{Cu}$ catalyst. Angew. Chem. Int. Ed. Engl. 127, 14914-14918 (2015).

\section{Acknowledgements}

We acknowledge Anatoly Frenkel for helpful discussions regarding the XAFS analysis. This work was funded by the German Federal Ministry of Education and Research (Bundesministerium für Bildung und Forschung, BMBF) under grant \#03SF0523 'CO2EKAT' and the Cluster of Excellence RESOLV at RUB (EXC 1069) funded by the Deutsche Forschungsgemeinschaft. In addition, financial support from the US National Science Foundation (NSF-Chemistry 1213182 an NSF-DMR 1207065) and the Office of Basic Energy Sciences of the US Department of Energy (DE-FG02-08ER15995) is greatly appreciated. Work at beamline BL2-2 at SSRL was supported in part by the U.S. DOE Grant No. DE-SC0012653 to the Synchrotron Catalysis Consortium. E.A.S. acknowledges support to the Center for Functional Nanomaterials, which is a U.S. DOE Office of Science Facility, at Brookhaven National Laboratory under Contract No. DE-SC0012704. C.S.B. and J.C.Y. acknowledges support by the Office of Basic Energy Sciences of the US Department of Energy (DE-FG02-03ER15476) and the US National Science Foundation (NSF CHE 1534630) in collaboration with UT Austin. Transmission electron microscopy work was performed at the National Center for Electron Microscopy at the Molecular Foundry at Lawrence Berkeley National Laboratory which is supported by the Office of Science, Office of Basic Energy Sciences, of the U.S. Department of Energy under Contract No. DE-AC02-05CH11231.

\section{Author contributions}

H.M. synthesized the samples, and A.S.V. performed all electrochemical measurements I.Z. performed the SEM measurements. K.K. and E.A.S. prepared cross-sections of the samples for TEM. C.S.B. and J.C.Y. performed TEM and EDS measurements, and performed SAED and porosity analysis. H.M., I.S., I.Z., Y.C., and B.R.C. performed the XAFS measurements, H.M. and B.R.C. analysed and interpreted the XAFS data. A.S.V. and P.S. analysed the electrochemical data. H.M., A.S.V., P.S. and B.R.C. wrote the manuscript. B.R.C. designed the experiment.

\section{Additional information}

Supplementary Information accompanies this paper at http://www.nature.com/ naturecommunications

Competing financial interests: The authors declare no competing financial interests.

Reprints and permission information is available online at http://npg.nature.com/ reprintsandpermissions/

How to cite this article: Mistry, H. et al. Highly selective plasma-activated copper catalysts for carbon dioxide reduction to ethylene. Nat. Commun. 7:12123 doi: 10.1038/ ncomms12123 (2016)

(c) (i) This work is licensed under a Creative Commons Attribution 4.0 International License. The images or other third party material in this article are included in the article's Creative Commons license, unless indicated otherwise in the credit line; if the material is not included under the Creative Commons license, users will need to obtain permission from the license holder to reproduce the material. To view a copy of this license, visit http://creativecommons.org/licenses/by/4.0/

(C) The Author(s) 2016 


\section{Corrigendum: Highly selective plasma-activated copper catalysts for carbon dioxide reduction to ethylene}

Hemma Mistry, Ana Sofia Varela, Cecile S. Bonifacio, loannis Zegkinoglou, llya Sinev, Yong-Wook Choi, Kim Kisslinger, Eric A. Stach, Judith C. Yang, Peter Strasser \& Beatriz Roldan Cuenya

Nature Communications 7:12123 doi: 10.1038/ncomms12123 (2016); Published 30 Jun 2016; Updated 12 Sep 2016

An incorrect version of the Supplementary Information was inadvertently published with this Article in which the image for Supplementary Fig. 7 was missing. The Article has now been updated to include the correct version of the Supplementary Information.

cc) This work is licensed under a Creative Commons Attribution 4.0 International License. The images or other third party material in this article are included in the article's Creative Commons license, unless indicated otherwise in the credit line; if the material is not included under the Creative Commons license, users will need to obtain permission from the license holder to reproduce the material. To view a copy of this license, visit http://creativecommons.org/licenses/by/4.0/

(C) The Author(s) 2016 